03,13

\title{
Электронная структура молибдена, окисленного на воздухе
}

\author{
() П.А. Дементьев ${ }^{1}$, Е.В. Иванова ${ }^{1}$, М.Н. Лапушкин ${ }^{1}$, Д.А. Смирнов ${ }^{2}$, С.Н. Тимошнев ${ }^{3}$ \\ ${ }^{1}$ Физико-технический институт им. А.Ф. Иофрфе РАН, \\ Санкт-Петербург, Россия \\ ${ }^{2}$ Institut für Festkörper- und Materialphysik, Technische Universität, \\ Dresden, Germany \\ ${ }^{3}$ Санкт-Петербургский национальный исследовательский Академический университет РАН, \\ Санкт-Петербург, Россия \\ E-mail: lapushkin@ms.ioffe.ru
}

Поступила в Редакцию 11 июня 2019 г.

В окончательной редакции 11 июня 2019 г.

Принята к публикации 17 июня 2019 г.

\begin{abstract}
Проведены исследования методом фотоэлектронной спектроскопии in situ в сверхвысоком вакууме электронной структуры чистой поверхности молибдена, окисленного на воздухе, и при адсорбции натрия Na при субмонослойных покрытиях. Изучены спектры фотоэмиссии из валентной зоны и остовных уровней $\mathrm{O} 1 s$, $\mathrm{O} 2 s$, Мо $4 s$ и Na $2 p$ при синхротронном возбуждении в диапазоне энергий фотонов $80-600 \mathrm{eV}$. Найдено изменение спектра остовных уровней кислорода, связанных с замещением атомов водорода в гидроксильной группе атомами натрия. Исследована топография поверхности и катодолюминесценция окисла молибдена.
\end{abstract}

Ключевые слова: Окисел молибдена, фотоэмиссия, АСМ, катодолюминесценция.

DOI: 10.21883/FTT.2019.11.48402.514

\section{1. Введение}

Окислы молибдена и, в частности, $\mathrm{MoO}_{3}$ нашли широкое применение в электронике, при создании различных сенсоров и датчиков, в накопителях энергии, в электрои фотохромных системах, солнечных элементах, катализаторах в окислительных (восстановительных) реакций и т.д. Окислы молибдена широко используются в качестве эмиттеров при термической ионизации металлов и органических молекул [1], а также в детекторах органических азотсодержащих молекул, работающих на воздухе при нормальном давлении [1-4]. Окисел молибдена является модельной подложкой, на которой исследуется электронно-стимулированная десорбция атомов щелочных металлов [5].

Существуют различные методы получения пленок оксида молибдена: это испарение различными способами окислов молибдена в вакууме, жидкофазные способы, включая электрохимический синтез, и т.д. [6]. Одним из простых и дешевых методов получения тонких пленок окисла молибдена является прогрев молибдена в атмосфере кислорода при различных давлениях.

Оксид молибдена $\mathrm{MoO}_{3}$ имеет две кристаллические структуры: термодинамически стабильную орторомбическую фазу $\alpha$-фазу и метастабильную моноклинную $\beta$-фазу. Ширина запрещенной зоны $\mathrm{MoO}_{3}$ около $3.0 \mathrm{eV}$. Расчеты показывают, что валентная зона сформирована из состояний $\mathrm{O} 2 p$ с незначительной примесью Мо $4 d$ состояний [7-10]. Электронная структура хорошо изучена для образцов, полученных различными способами, но исследования в основном направлены на изучение как валентной зоны, так и формы спектров остовных уровней молибдена, которые зависят как от внешних условий, так и методов приготовления [11-14]. Значительно меньше работ посвящено исследованию формы остовных уровней кислорода [13-16], в которых было показано влияние гидроксила и адсорбированной воды на форму спектра остовных уровней кислорода. Известно, что экспозиция на воздухе или в атмосфере кислорода пленок $\mathrm{MoO}_{3}$ понижает работу выхода с $6.75 \mathrm{eV}$ до $5.3 \mathrm{eV}$ [17-19], а последующий прогрев в вакууме при температуре $730 \mathrm{~K}$ восстанавливает работу выхода до $6.4 \mathrm{eV}$. Выдержка полученных в сверхвысоком вакууме пленок окисла в течение часа на воздухе не приводит к заметным изменениям в спектре остовных линий, происходит только лишь незначительное, по мнению авторов, восстановление окисла молибдена [20].

В работе была поставлена задача исследования электронной структуры тонкой пленки окисла молибдена, полученной при прогреве в атмосфере воздуха, для лучшего понимания процесса термической ионизации атомов и молекул и электронной стимулированной десорбции атомов щелочных металлов с окисленного молибдена.

\section{2. Эксперимент}

В настоящей работе тонкие пленки окисла молибдена были получены при окислении Мо-фольги при температуре $1000 \mathrm{~K}$ при давлении воздуха $1 \mathrm{~atm}$, что соответствует условиям получения тонких пленок окисла молибдена для детекторов органических молекул, работающих при атмосферном давлении. 
Фотоэмиссионные исследования были выполнены в Российско-Германской лаборатории на синхротроне HBZ BESSY II (Берлин, Германия) с использованием метода фотоэлектронной спектроскопии (ФЭС) при возбуждении в диапазоне энергий фотонов 80-600 eV. Регистрировались фотоэлектроны по нормали к поверхности, возбуждающий пучок падал на поверхность образца под углом $45^{\circ}$. Исследования окисленной тонкой пленки молибдена $\left(\mathrm{MoO}_{3}\right)$ и с напыленным субмонослойным покрытием натрия проводились in situ в вакууме $P<5 \cdot 10^{-10}$ Torr при комнатной температуре. Регистрировались спектры фотоэмиссии в области валентной зоны, а также спектры остовных уровней О $1 s, \mathrm{O} 2 s$, Mo $4 s$ и $\mathrm{Na} 2 p$. Полное энергетическое разрешение было $50 \mathrm{meV}$. Для всех приведенных ниже спектров фон был вычтен по методу Ширли (Shirley).

Спектры катодолюминесценции (КЛ) были получены на электронно-зондовом микроанализаторе CAMЕВАХ (Cameca, Франция), оснащенном оптическими спектрометрами оригинальной конструкции. Условия эксперимента: энергия электронов $5 \mathrm{keV}$, ток электронного пучка $50 \mathrm{nA}$, диаметр пучка $5 \mu \mathrm{m}$.

Поверхностная морфология образцов исследована при помощи атомно-силовой микроскопии (АСМ). На рис. 1 приведено характерное АСМ изображение поверхности $\mathrm{MoO}_{3}$ после напыления $\mathrm{Na}$. Поверхность является сильно зернистой, с характерными линейными размерами зерен порядка $200 \mathrm{~nm}$ и высотой около 30-50 nm. Кроме того, на поверхности присутствуют шарообразные частицы, связанные либо с процессом создания окисла, либо с напылением $\mathrm{Na}$.

Перед фотоэмиссионными исследованиями образцы подвергались отжигу в высоком вакууме при температуре $\sim 900 \mathrm{~K}$. Атомарно-чистый $\mathrm{Na}$ напылялся на чистую поверхность образца из стандартного источника. Отметим, что за один монослой (ML) Na принимается концентрация $1.0 \cdot 10^{15}$ atom $/ \mathrm{cm}^{2}$, при которой формируется укомплектованный слой атомов Na. Покрытие атомов натрия определялось по ослаблению остовных пиков кислорода О $1 s$ и О $2 s$, при энергии возбуждения фотоэмиссии $h v=600 \mathrm{eV}$ по известным значениям глубины выхода фотоэлектронов в работе [21].

На рис. 2 представлены спектры фотоэмиссии из остовных уровней $\mathrm{O} 2 s$ и О $1 s$ для чистой поверхности $\mathrm{MoO}_{3}$ при энергии возбуждения $600 \mathrm{eV}$. Спектр фотоэмиссии при энергии возбуждения $h v=600 \mathrm{eV}$ из остовного уровня О $1 s$ соответствуют поверхностной фотоэмиссии, так как кинетическая энергия фотоэлектронов близка к минимуму выхода на универсальной кривой выхода фотоэлектронов от кинетической энергии [22]. А спектр фотоэмиссии при энергии возбуждения $h v=600 \mathrm{eV}$ остовного уровня О $2 s$ отражает выход из глубины пленки, т.н. объемной фотоэмиссии, при этом наблюдается два четко выраженных пика при $E_{B}=23.8$ и $25.6 \mathrm{eV}$. Как показывают многочисленные исследования, широкий пик остовного уровня кислорода O $1 s$ связан с тем, что вклад дает не только кислород
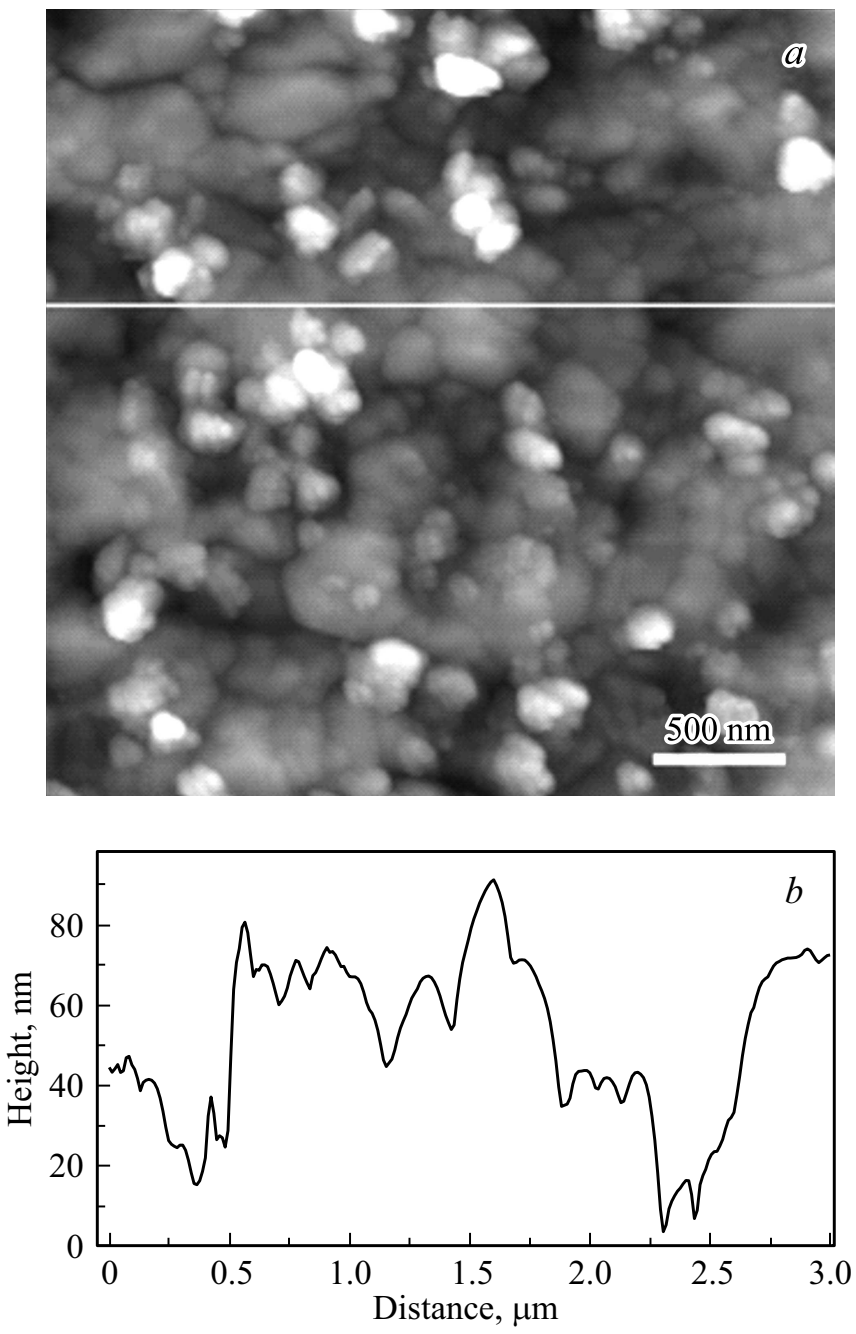

Рис. 1. АСМ-изображение поверхности $\mathrm{MoO}_{3}$ после напыления $\mathrm{Na}(a)$, профиль поверхности $(b)$ по светлой линии на АСМ-изображении.

в соединении $\mathrm{MoO}_{3}$, но и гидроксил $(\mathrm{OH})$. Пик с меньшей энергией связи $E_{B}=528.4 \mathrm{eV}$ приписывается гидроксилу, а $E_{B}=530.2 \mathrm{eV}$ - кислороду в составе окисла. Можно считать, что аналогичное разделение пика на два можно сделать и для остовного уровня O $2 s$ : пик с меньшей энергией связи $E_{B}=23.8 \mathrm{eV}$ приписывается гидроксилу, а с большей энергией связи $E_{B}=25.6 \mathrm{eV}$ - кислороду в составе окисла. Расчет адсорбции воды на $\mathrm{WO}_{3}(001)$ [23] показывает, что диссоциация воды предпочтительно происходит на вакансиях кислорода. Однако ряд других исследований показывает, что возможно образование в этом случае на поверхности $\mathrm{H}_{2} \mathrm{MoO}_{4}$, например [24,25]. Наличие гидроксила на поверхности может указывать, что происходит диссоциативная адсорбция воды в процессе формирования окисла молибдена. Данный факт нас приводит к выводу, что при окислении на воздухе как на поверхности, так и в объеме окисла обнаруживается большое количество гидроксилов, даже несмотря на высокую температуру окисления 


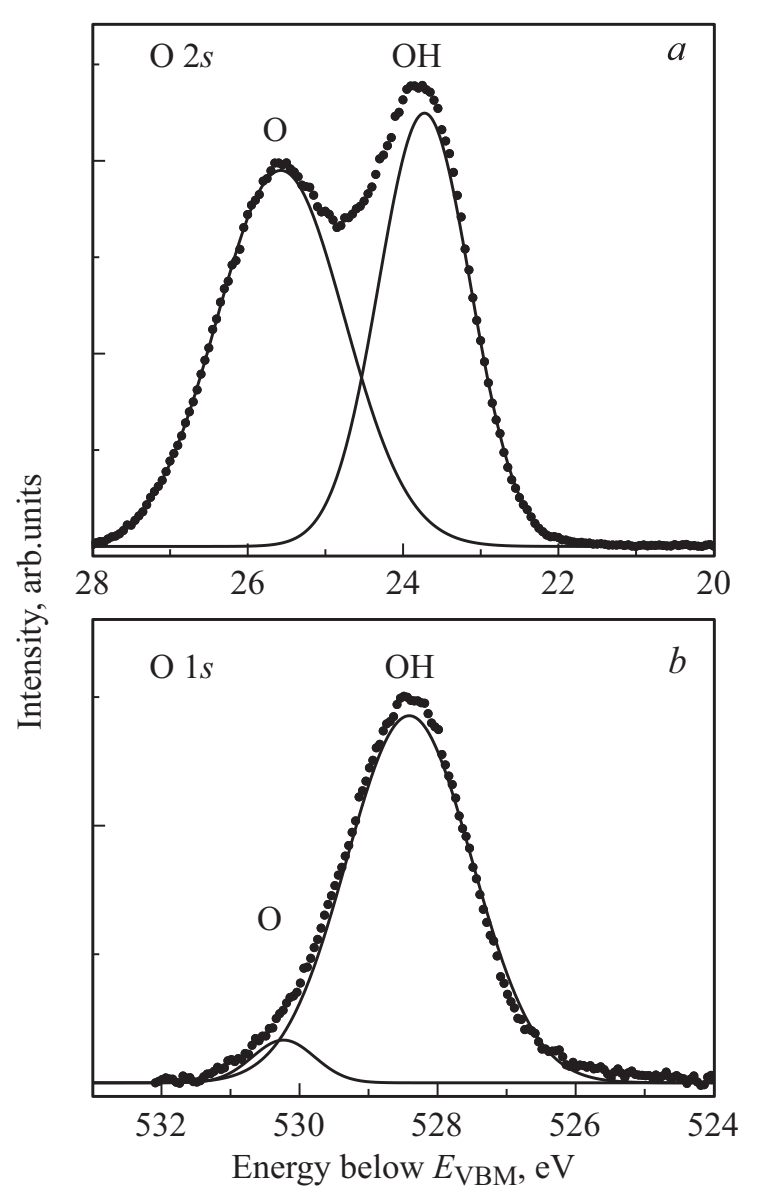

Рис. 2. Спектры нормальной фотоэмиссии остовных уровней $\mathrm{O} 2 s(a)$ и О $1 s(b)$ для чистой поверхности $\mathrm{MoO}_{3}$. Энергия возбуждения $h v=600 \mathrm{eV}$.

молибдена $1000 \mathrm{~K}$. Анализ структуры спектров показывает, что на поверхности намного большая концентрация гидроксилов по сравнению с объемом. Это совпадает с литературными данными [13], в которых показано, что для удаления гидроксилов с поверхности требуется как большие температуры, так и более длительные времена прогрева.

Адсорбция 0.7 монослоя натрия приводит к изменениям спектров остовных уровней О $2 s$ и О $1 s$ (рис. 3). Происходит перераспределение компонентов пика О $2 s$, связанных с кислородом в составе окисла и в составе гидроксила, при этом стал более интенсивным пик, связанный с окислом молибдена. Площадь под пиком остается неизменной, однако площадь под пиком гидроксила уменьшается на треть. Значительно большие изменения происходят на поверхности (пик О $1 s$ ): составляющая пика, связанная с гидроксилом, также уменьшается на одну треть, однако возрастает компонента, связанная с кислородом в составе окисла. Мы полагаем, что на поверхности происходит замещение водорода в гидроксильной группе на Na. Тогда можно предположить следующие возможные реакции на поверхности: адсорбция воды приводит к образованию „молибденовой кислоты“, как это было получено в работах $[25,26]$ :

$$
\mathrm{MoO}_{3}+\mathrm{H}_{2} \mathrm{O} \rightarrow \mathrm{H}_{2} \mathrm{MoO}_{4} .
$$

А адсорбция $\mathrm{Na}$ при его малых концентрациях на поверхности приводит к протеканию следующей реакции:

$$
\mathrm{H}_{2} \mathrm{MoO}_{4}+\mathrm{Na} \rightarrow \mathrm{NaHMoO}_{4}+\mathrm{H}(\text { ads }) .
$$

Образование $\mathrm{NaHMoO}_{4}$ на поверхности $\mathrm{MoO}_{3}$ было показано ранее [27]. А при достаточно большой концентрации атомов натрия возможно протекание реакции с десорбцией водорода и образованием на поверхности молибдата натрия:

$$
\mathrm{H}_{2} \mathrm{MoO}_{4}+2 \mathrm{Na} \rightarrow \mathrm{Na}_{2} \mathrm{MoO}_{4}+\mathrm{H}_{2} \uparrow \text {. }
$$

Отметим, что не было зарегистрировано заметных изменений в спектрах остовных уровней Мо при адсорбции $\mathrm{Na}$, характерный спектр которых приведен на рис. $4, b$. При чуть больших энергиях связи, чем энергия

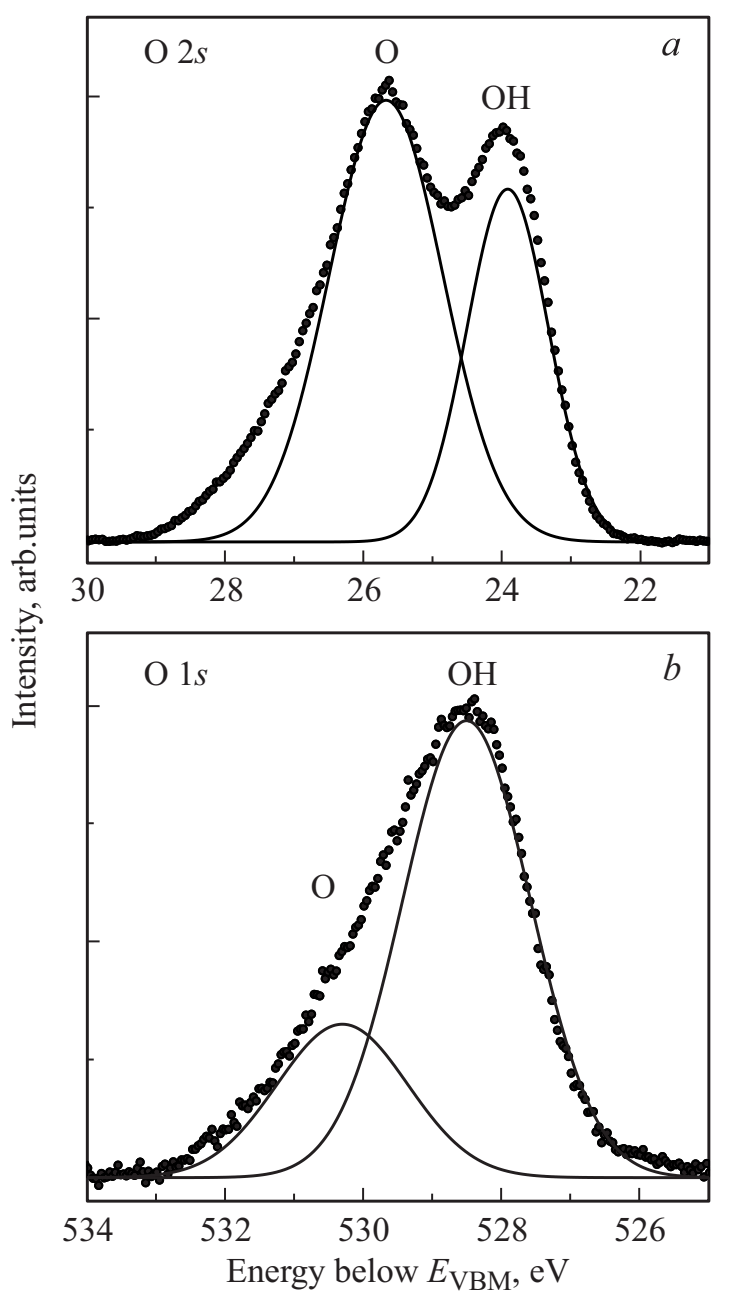

Рис. 3. Спектры нормальной фотоэмиссии остовных уровней $\mathrm{O} 2 s(a)$ и $\mathrm{O} 1 s(b)$ для субмонослойного покрытия $\mathrm{Na} \theta=0.7 \mathrm{ML}$ на поверхности $\mathrm{MoO}_{3}$. Энергия возбуждения $h v=600 \mathrm{eV}$. 


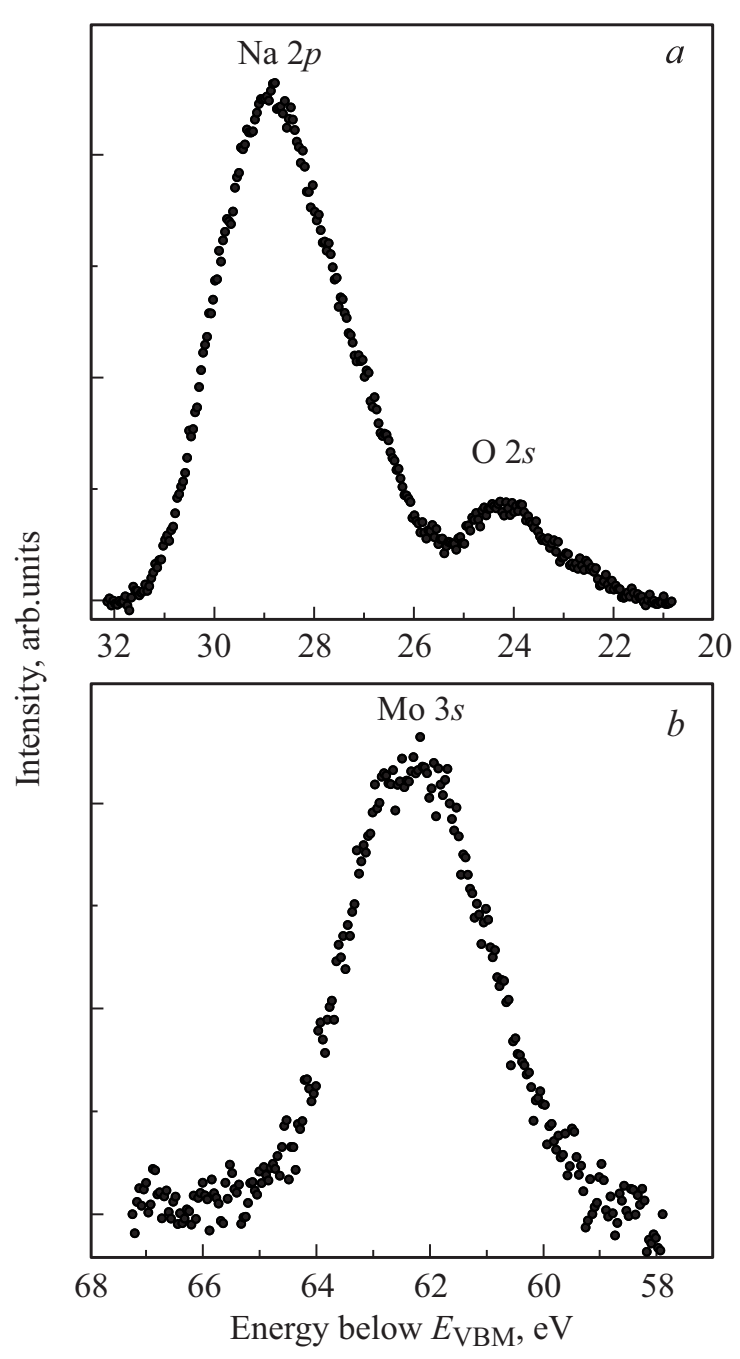

Рис. 4. Спектры фотоэмиссии остовных уровней $\mathrm{Na} 2 p(a)$ и Мo $3 s(b)$ для субмонослойного покрытия $\mathrm{Na} \theta=0.7 \mathrm{ML}$ на поверхности $\mathrm{MoO}_{3}$. Энергия возбуждения $h v=120(a)$ и $h v=80 \mathrm{eV}(b)$.

связи О $2 s$ наблюдается пик остовного уровня $\mathrm{Na} 2 p$, форма и энергетическое положение которого не изменяется с ростом натриевого покрытия, увеличивается лишь интенсивность.

Нормированные спектры фотоэмиссии в области валентной зоны $\mathrm{MoO}_{3}$ представлены на рис. 5 для энергий возбуждения в диапазоне от 80 до $600 \mathrm{eV}$. Спектры приведены к энергии вершины валентной зоны на поверхности $E_{\mathrm{VBM}}$, которая определяется линейной аппроксимацией низкоэнергетического края спектра. В области валентной зоны спектр $\mathrm{MoO}_{3}$ не имеет особенностей и имеет ширину $\sim 11 \mathrm{eV}$. Форма спектров для всех исследованных энергий совпадает по форме со спектром для чистой поверхности и отличается лишь интенсивностью, за исключением небольшой особенности при $E_{B}=6 \mathrm{eV}$ для $h v=600 \mathrm{eV}$. Поверхностных состояний в запрещенной зоне обнаружено не было. Полученные нами спектры находятся также в хорошем согласии с экспериментальными данными, например [18,22,23,28], в которых не наблюдается особенностей в спектре валентной зоны.

Адсорбция атомов натрия в субмонослойном режиме не приводит к изменению в спектре валентной зоны, происходит только незначительное изменение интенсивности спектра валентной зоны для всех исследованных энергий возбуждения фотоэмиссии.

На рис. 6 приведены спектры катодолюминесценции исходной пленки оксида молибдена и пленки после нагрева до $900 \mathrm{~K}$ и напыления субмонослойной пленки натрия $0.7 \mathrm{ML}$. Наблюдается четко выраженный максимум при энергии $2.4 \mathrm{eV}$ и высокоэнергетический медленный спад. Напыление натрия и прогрев пленки приводит к синему сдвигу спектра. Максимум КЛ смещается на $0.1 \mathrm{eV}$. Полученные нами спектры отличаются от измеренных раннее спектров КЛ [29] и фотолюминесценции [30], в этих работах максимум интенсивности находиться в УФ диапазоне при $3.4-3.6 \mathrm{eV}$. Ширина запрещенной зоны объемного $\mathrm{MoO}_{3}$ составляет $2.9-3.0 \mathrm{eV}[31,32]$. Однако в [30] было продемонстрированно, что в тонких пленках ширина запрещенной зоны может достигать $3.2-3.6 \mathrm{eV}$. Также в статье [30] показано, что при отжиге выше $473 \mathrm{~K}$ происходит увеличение ширины запрещенной зоны. Спектры КЛ аппроксимированы суммой трех гауссовых полос, что позволяет четко выделить синий

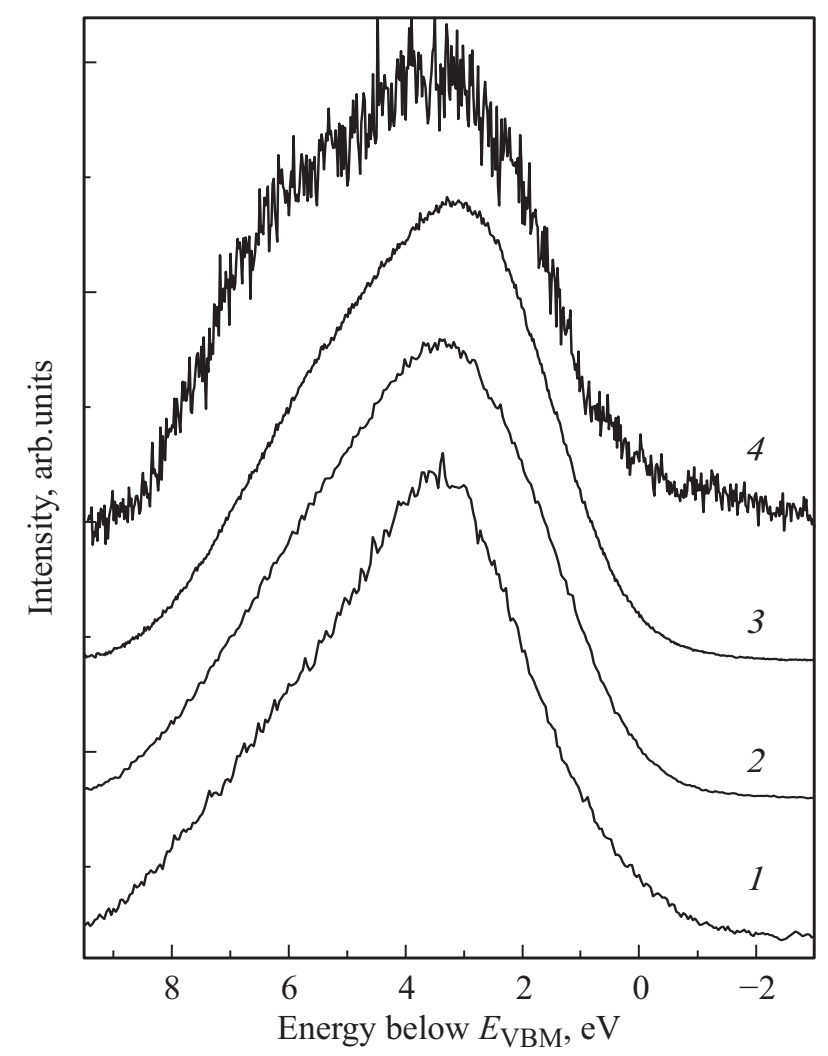

Рис. 5. Нормированные спектры фотоэмиссии в области валентной зоны для чистой поверхности $\mathrm{MoO}_{3}$ при различных энергиях возбуждения: $1-h v=80 \mathrm{eV}, 2-h v=100 \mathrm{eV}$, $3-h v=120 \mathrm{meV}, 4-h v=600 \mathrm{eV}$. 


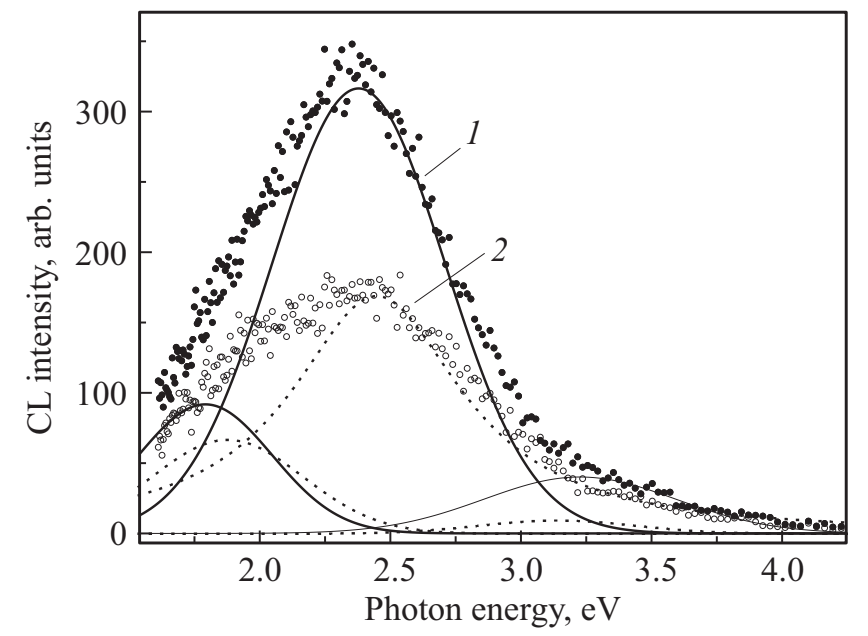

Рис. 6. Спектры катодолюминесценции: 1 - исходная пленка оксида молибдена, 2 - пленка оксида молибдена после нагрева до $900 \mathrm{~K}$ и напыления натрия. Аппроксимация спектров катодолюминесценции суммой гауссовых полос: сплошная линия для исходной пленки $\mathrm{MoO}_{3}$, пунктирная линия для пленки $\mathrm{MoO}_{3}$ после нагрева до $900 \mathrm{~K}$ и напыления натрия.

сдвиг всех полос после нагрева образцов и напыления натрия. Синий сдвиг в спектрах пленки после нагрева можно связать с увеличением ширины запрещенной зоны после прогрева окисла молибдена. Люминесценция в видимом диапазоне скорей всего связана с точечными дефектами в оксиде молибдена, например, полосы в УФ диапазоне связывают с вакансией кислорода, захватившей электрон [33]. Падение интенсивности после напыления натрия скорее всего связано с образованием на поверхности образца соединений, например, $\mathrm{Na}_{2} \mathrm{MoO}_{4}$.

\section{3. Заключение}

Таким образом, в настоящей работе впервые исследована электронная структура поверхности окисленного на воздухе молибдена, а также адсорбция натрия на поверхности. Анализ формы спектров остовных уровней О $1 s, \mathrm{O} 2 s$ при синхротронном возбуждении в диапазоне энергий фотонов 80-600 eV показал, что в процессе окисления молибдена на воздухе происходит диссоциативная адсорбция паров воды. Адсорбция атомов натрия приводит к изменению спектров остовных уровней $\mathrm{O} 1 s$, O $2 s$, которые можно объяснить реакцией между атомами натрия и гидроксильной группой. Влияние адсорбции атомов натрия на спектры остовных уровней молибдена и валентной зоны обнаружено не было. Показано, что в спектрах КЛ наблюдаются полосы, связанные с точечными дефектами оксида молибдена. Дополнительных полос после напыления натрия не наблюдается, изменения спектра КЛ скорей всего связано с изменением ширины запрещенной зоны после прогрева.

\section{Благодарности}

Авторы признательны Helmholtz-Zentrum Berlin за возможность использования синхротронного излучения и Д.О. Кулешову за обсуждение результатов.

\section{Конфликт интересов}

Авторы заявляют, что у них нет конфликта интересов.

\section{Список литературы}

[1] Э.Я. Зандберг. ЖТФ 65, 1 (1995).

[2] Э.Я. Зандберг, А.Г. Каменев, В.И. Палеев, У.Х. Расулев. Журнал аналитической химии XXXV, 1188 (1980).

[3] И.А. Бураков, Е.В. Крылов, А.Л Макасей, Э.Г. Назаров, В.В. Первухин, У.Х. Расулев. Письма в ЖТФ 17, 60 (1991).

[4] В.И. Капустин, А.П. Коржавый. Росс. технол. 4, 3 (2016).

[5] В.Н. Агеев, Ю.А. Кузнецов. ФТТ 40, 768 (1998).

[6] I.A. de Castro, R.S. Datta, J.Z. Ou, S. Sriram, T. Daeneke, K. Kalantar-zadeh. Adv. Mater. 29, 1701619 (2017).

[7] A.D. Sayede, T. Amriou, M. Pernisek, B. Khelifa, C. Mathieu. Chem. Phys. 316, 72 (2005).

[8] D.O. Scanlon, G.W. Watson, D.J. Payne, G.R. Atkinson, R.G. Egdell, D.S.L. Law. J. Phys. Chem. C 114, 4636 (2010).

[9] R. Tokarz-Sobieraj, K. Hermann, M. Witko, G. Mestl, R. Schlögl. Surf. Sci. 489, 107 (2001).

[10] Q. Qu, W.B. Zhang, K. Huang, H.M. Chen. Comput. Mater Sci. 130, 242 (2017).

[11] Y.Zh. Wang, M. Yang, D.C. Qi, S. Chen, W. Chen, A.T.S. Wee, X.Y. Gao. J. Chem. Phys. 134, 034706 (2011).

[12] A. Borgschulte, O. Sambalova, R. Delmelle, S. Jenatsch, R. Hany, F. Nüesch. Sci. Rep. 7, 40761 (2017).

[13] P.C. Kao, Z.H. Chen, H.E. Yen, T.H. Liu, C.L. Huang. Jpn. J. Appl. Phys. 57, 03DA04 (2018).

[14] A.T. Martí-Luengo, H. Köstenbauer, J. Winkler, A. Bonanni. AIP Adv. 7, 015034 (2017).

[15] G.E. Buono-Core, A.H. Klahna, C. Castillo, E. Muñoz, C. Manzur, G. Cabellob, B. Chornik. J. Non-Cryst.Solids 387, 21 (2014).

[16] J. Song, X. Ni, D. Zhang, H. Zheng. Solid State Sci. 8, 1164 (2006).

[17] A.A. Bortotia, A.F. Gavanskia, Y.R. Velazquezb, A. Gallia, E.G. de Castro. J. Solid State Chem. 252, 111 (2017).

[18] I. Irfan, H. Ding, Y. Gao, C. Small, D.Y. Kim, J. Subbiah, F. So. Appl. Phys. Lett. 96, 243307 (2010).

[19] I. Irfan, A.J. Turinske, Z. Bao, Y. Gao. Appl. Phys. Lett. 101, 093305 (2012).

[20] C. Wang, I. Irfan. JVST B 32, 040801 (2014).

[21] S. Tanuma, C.J. Powell, D.R. Penn. Surf. Interface Anal. 2011 43, 689 (2011).

[22] I. Lindau, W.E. Spicer. J. Electr. Spectroscopy 3, 409 (1974).

[23] L. Zhang, B. Wen, Y.N. Zhu, Z. Chai, X. Chen, M. Chen. Comput. Mater. Sci. 150, 484 (2018).

[24] Y.Z. Wang, M. Yang, D.C. QI, S. Chen, W. Chen, A.T.S. Wee, X.Y. Gao. J. Chem. Phys. 134, 034706 (2011).

[25] T.C. Arnoldussen. J. Electrochem. Soc. 123, 527 (1976).

[26] N. Desai, S. Mali, V. Kondalka, R. Mane, C. Hong, P. Bhosale. J Nanomed Nanotechnol 6, 338 (2015). 
[27] H. Akutsu, S. Yamaguchi, K. Otsubo, M. Tamaoki, A. Shimazaki, R. Yoshimura, F. Aiga, T. Tada. Proc. SPIE 7028, 702829 (2008).

[28] A.T. Martí-Luengo, H. Köstenbauer, J. Winkler, A. Bonanni. AIP Adv. 7, 015034 (2017).

[29] K. Koike, R. Wada, S. Yagi, Y. Harada, S. Sasa, M. Yano. Jpn. J. Appl. Phys. 53, 05FJ02 (2014).

[30] I. Navas, R. Vinodkumar, V.P. Mahadevan Pillai. Appl. Phys. A 103, 373 (2011).

[31] T. Toyoda, H. Nakanishi, S. Endo, T. Irie. J. Phys. D 18, 747 (1985).

[32] H. Simchi, B.E. McCandless, T. Meng, J.H. Boyle, W.N. Shafarman. J. Appl. Phys. 114, 013503 (2013).

[33] Л.Н. Бугерко, Н.В. Борисова, В.Э. Суровая, Г.О. Еремеева. Ползуновский вестн. 1, 77 (2013).

Редактор К.В. Емцев 